\title{
Penerapan Internet of Things (IoT) Pada Sistem Kendali Lampu Berbasis Mobile
}

\author{
Rometdo Muzawi ${ }^{1}$, Wahyu Joni Kurniawan ${ }^{2}$ \\ Prorgram Studi Manajemen Informatika STMIK Amik Riau \\ Prorgram Studi Sistem Informasi STIKOM Pelita Indonesia \\ Jln. Purwodadi Indah KM.10, Sidomulyo Barat, Tampan-Pekanbaru \\ Jln. Jend. Ahmad Yani No.70, Kota Baru, Pekanbaru \\ rometdomuzawi@stmik-amik-riau.ac.id,wahyu.jonikurniawan@lecturer.pelitaindonesia.ac.id
}

\begin{abstract}
Internet of things (IoT) is a hardware (Raspberry Pi) that can connect to the internet with the aim to expand the internet network that is connected thoroughly to the hardware. The development of the Internet of things (IoT) has been widely used, especially in this day and age, one of the utilization of this IoT technology is the control of electronic room light equipment through global network controlled via smartphone that can be operated remotely. This research aims to build a remotecontrol device by utilizing internet technology to perform the process of controlling the lights based on the Internet of things (IoT). This research is done by building a prototype with mobile based application using python and php programming language. In this research there is a feature of controlling the room lights with the first condition of control of one lamp used to turn one room light and the second condition is used to turn the lights simultaneously.
\end{abstract}

Keywords: IoT, Prototype, Raspberry Pi, Mobile.

\begin{abstract}
Abstrak
Internet of things (IoT) merupakan sebuah perangkat keras (Raspberry Pi) yang dapat tersambung dengan internet dengan tujuan untuk memperluas jaringan internet yang terhubung secara menyeluruh pada hardware. Perkembangan Internet of things (IoT) telah banyak digunakan terutama pada zaman sekarang ini, salah satu dimanfaatkannya teknologi IoT ini adalah pengendalian peralatan elektronik lampu ruangan melalui jaringan internet global yang dikontrol melalui smartphone yang dapat dioperasikan dari jarak jauh. Penelitian ini bertujuan untuk membangun perangkat remote-control dengan memanfaatkan teknologi internet untuk melakukan proses pengendalian lampu berbasis Internet of things (IoT) . Penelitian ini dilakukan dengan membangun sebuah prototype dengan aplikasi berbasis mobile menggunakan bahasa pemrograman python dan php. Dalam penelitian ini terdapat fitur pengendalian lampu ruangan dengan kondisi pertama kendali satu lampu yang digunakan untuk menghidupkan satu lampu ruangan dan kondisi kedua digunakan untuk menghidupkan lampu secara bersamaan.
\end{abstract}

Kata Kunci: IoT, Prototype, Raspberry Pi, Mobile.

\section{PENDAHULUAN}

Internet of things (IoT) merupakan sebuah perangkat keras (Raspberry Pi) yang dapat tersambung dengan internet dengan tujuan untuk memperluas jaringan internet yang terhubung secara menyeluruh pada hardware [1]. Internet of things (IoT) bisa dimanfaatkan pada gedung untuk mengendalikan peralatan elektronik seperti lampu ruangan yang dapat dioperasikan dari jarak jauh melalui jaringan komputer, tidak dapat dipungkiri kemajuan teknologi yang sedemikian cepat harus bisa dimanfaatkan,dipelajari serta diterapkan dalam kehidupan sehari-hari. Contohnya adalah perkembangan teknologi yang bisa dimanfaatkan dari adanya koneksi internet ini bisa mengakses peralatan elektronik seperti lampu ruangan yang dapat dioperasikan dengan cara online melalui mobile. Sehingga, dapat memudahkan pengguna memantau ataupun mengendalikan lampu kapanpun dan dimanapun dengan catatan di lokasi yang akan diterapkan teknologi kendali jarak 
jauh mempunyai jaringan internet yang memadai. Sistem kendali jarak jauh, memudahkan pengguna dalam mengontrol lampu gedung yang jaraknya cukup jauh lokasinya. Sementara pada penelitian yang lain "Purwa Rupa Internet of things (IoT) Kendali Lampu Gedung "Teknologi sistem kendali ini dilakukannya dari sebuah komputer saja yang didalamnya terdapat sebuah sistem atau fitur software yang telah dibangun dan dirancang untuk melakukan tugas kendali tersebut terhadap lampu ruangan[2].

Dalam pengembangan dan perbaikan terhadap permasalahan diatas, maka pada penelitian ini peneliti menggunakan Rasberry Pi 3 . Rasberry Pi adalah salah satu komponen Internet of things (IoT) yang dapat diaplikasikan sebagai pengendali jarak jauh dengan jaringan internet yang dapat diterapkan pada peralatan elektronik seperti lampu. Perangkat tersebut dapat diakses dengan layanan internet melalui smartphone android dengan Internet Protocol sehingga tingkat efisiensi tenaga dan waktu jam kerja petugas serta dari segi penghematan energi listrik yang digunakan. Teknologi ini tepat untuk diterapkan karena untuk memudahkan petugas dalam melakukan pekerjaan tersebut. Berdasarkan uraian di atas, maka peneliti bermaksud untuk melakukan penelitian untuk merancang prototype dan membuat program aplikasi mobile dan python menggunakan Rasberry Pi 3 sebagai pengendali lampu jarak jauh dengan jaringan internet yang dapat diterapkan pada peralatan elektronik seperti lampu sehingga tingkat efisiensi tenaga dan waktu jam kerja petugas serta dari segi penghematan energi listrik yang digunakan.

\section{METODOLOGI PENELITIAN}

Adapun kerangka kerja dalam penelitian ini sebanyak 4 tahapan yang digambarkan berikut ini:

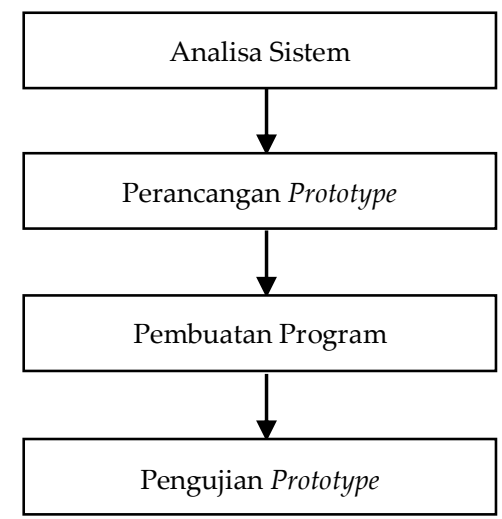

\section{A. Analisa Sistem}

Gambar 1. Alur Kerangka Kerja Penelitian

Analisis kebutuhan sistem ini ditujukan untuk menguraikan kebutuhankebutuhan yang harus disediakan oleh sistem agar dapat memenuhi kebutuhan pengguna dan sesuai dengan tujuan penelitian yaitu melakukan perancangan rancang bangun pengontrolan lampu berbasis internet of things menggunakan raspberry pi. Rancangan sistem ini menjelaskan kebutuhan antarmuka, kebutuhan data masukan dan data keluaran yang menunjukkan spesifikasi sistem yang dapat diakses.

\section{B. Analisa Fungsional}

Analisa Kebutuhan fungsional merupakan gambaran mengenai fungsi-fungsi 
yang dapat dilakukan oleh sistem ini. Kebutuhan fungsional sistem meliputi:

1) Sistem yang dirancang berbasis mobile.

2) pada sistem mobile harus terinstal di smartphone.

3) Adanya fasilitas mematikan lampu per ruangan dan keseluruhan lampu secara bersamaan.

\section{Analisa Non Fungsional}

Analisa Kebutuhan non-fungsional adalah kebutuhan sistem meliputi kinerja, kelengkapan operasi pada fungsi-fungsi yang ada, serta kesesuaian dengan lingkungan penggunanya. Kebutuhan nonfungsional ini melingkupi beberapa kebutuhan yang mendukung kebutuhan fungsional, rumusan kebutuhan nonfungsional meliputi:

1) Kebutuhan Operasional

a. Pada sistem mobile, wajib terkoneksi internet.

b. Pada sistem mobile, aplikasi dapat terinstal pada perangkat Android.

c. Pada sistem mobile, sistem hanya dapat diakses melalui file format.apk yang telah terinstal di perangkat Android.

d. User interface pada aplikasi dibuat dengan sederhana untuk memudahkan pengguna.

2) Performance sistem sistem yang dibangun merupakan aplikasi yang berjalan pada lingkungan perangkat bergerak. Terdapat beberapa keterbatasan yang ditemui pada perangkat. Oleh karena itu perlu diperhatikan guna menjadi acuan dalam pengembangan sistem, diantaranya:

a. Sumber daya listrik digunakan se efektif mungkin.

b. Tampilan aplikasi antarmuka disesuaikan dengan kebutuhan.

c. Merancang aplikasi dengan antarmuka yang sederhana namun tetap menarik dan mudah digunakan oleh pengguna.

\section{Perancangan Protoype}

Dalam membuat rancangan prototype sesuai data yang ada berdasarkan tahapan yang ditetapkan pada tahapan analisa data. Diperlukan rancangan sistem pengendalian lampu berbasis mobile.

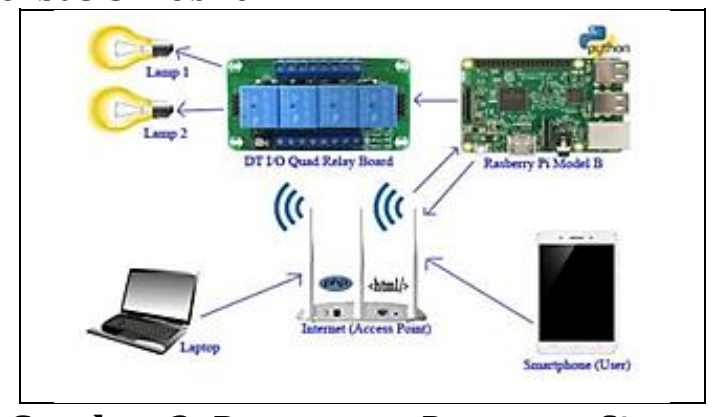

Gambar 2. Rancangan Prototype Sistem

\section{E. Pembuatan Program}

Membuat sebuah aplikasi dengan berbasiskan Rasberry Pi 3 dalam pengedalian lampu berbasis Mobile.

\section{F. Pengujian Prototype}

Menguji seluruh spesifikasi terstruktur dan aplikasi secara keseluruhan. Pada 
tahap ini dilakukan uji coba aplikasi yang telah selesai dibuat. Proses uji coba ini diperlukan untuk memastikan bahwa aplikasi yang telah dibuat sudah benar, sesuai dengan karakteristik yang ditetapkan dan tidak ada kesalahan yang terkandung didalamnya.

\section{HASIL DAN PEMBAHASAN}

\subsection{Perancangan Protype}

Dari perancangan rancang bangun pengontrolan lampu berbasis internet of things di atas dimulai pemakain DT Relay seperti gambar berikut:

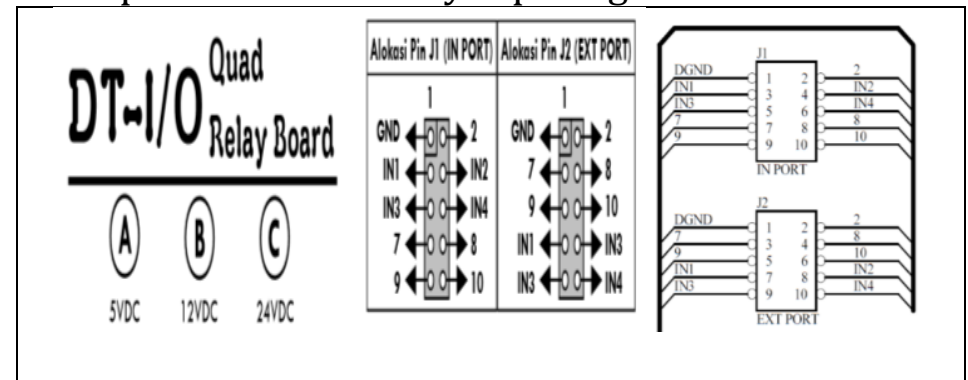

Gambar 3. Datasheet DT-I/O Quad Relay Board

Setelah DT- Relay, dilanjutkan mengatur Data Sheet Raspberry Pi 3 dengan tampilan seperti gambar berikut:

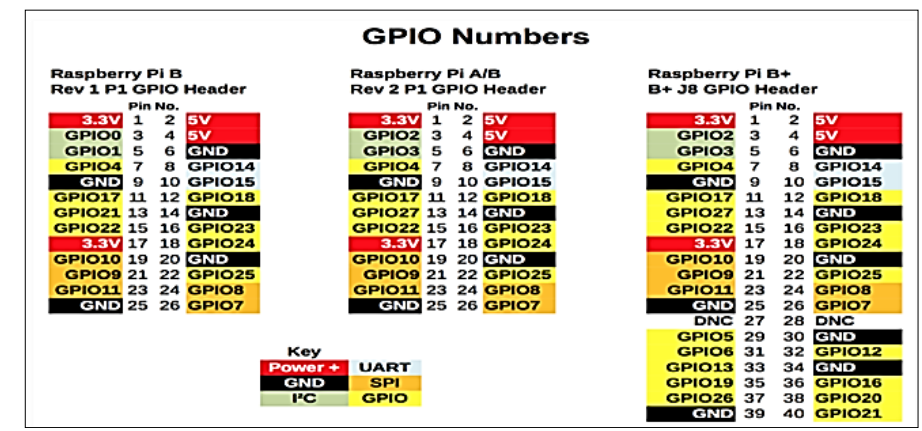

Gambar 4. Datasheet GPIO Numbers Raspberry Pi 3

Maka akan tampil, koneksi prototype DT-Relay dengan Raspeberry Pi 3 yang terhubung dengan menggunakan kabel pelangi. Tampilan sebagai berikut:

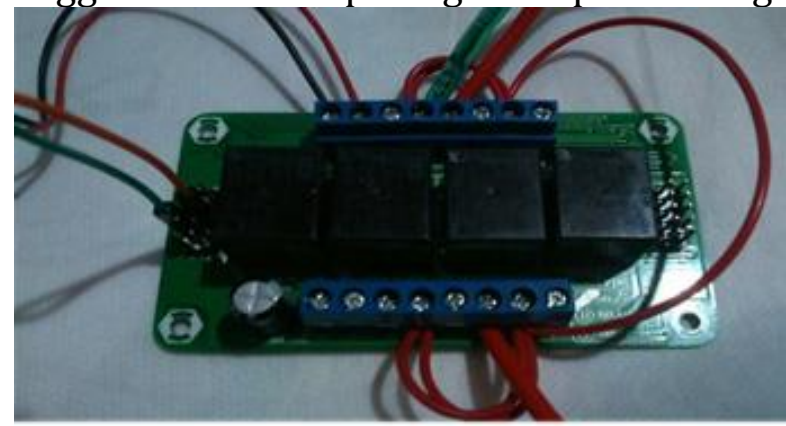

Gambar 5. Rangkaian DT-I/O Quad Relay Board dan Raspberry Pi 3

Setelah koneksi DT-Relay dan Raspberry Pi 3 terkoneksi lalu persiapkan 2 fitting lampu dengan bola lampu. Untuk tampilan lebih baik bisa kita gunakan akrilik untuk membatasi antara ruang lampu yang satu dengan yang lainnya. Dapat dilihat pada gambar berikut: 


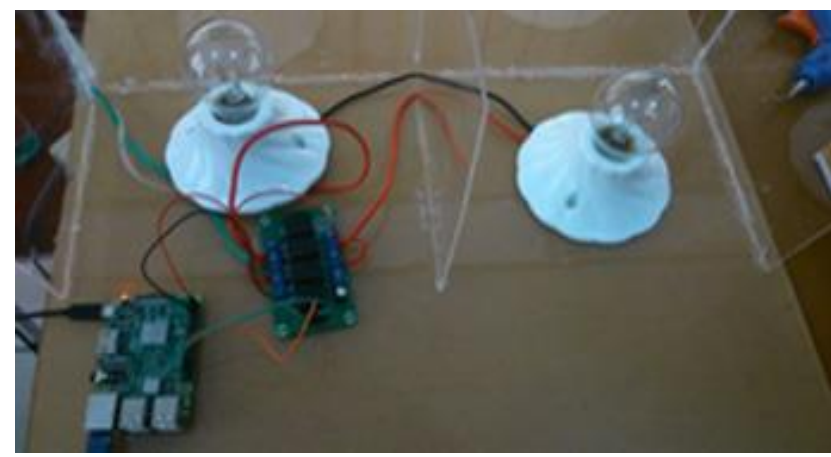

Gambar 6. Prototype Lampu IoT

\subsection{Pembuatan Program Python}

Dalam pembuatan program pengontrolan lampu berbasis internet of things peneliti menggunakan bahasa pemrograman python dan mobile, berikut tampilan pemrograman python nya:

\subsection{Implementasi}

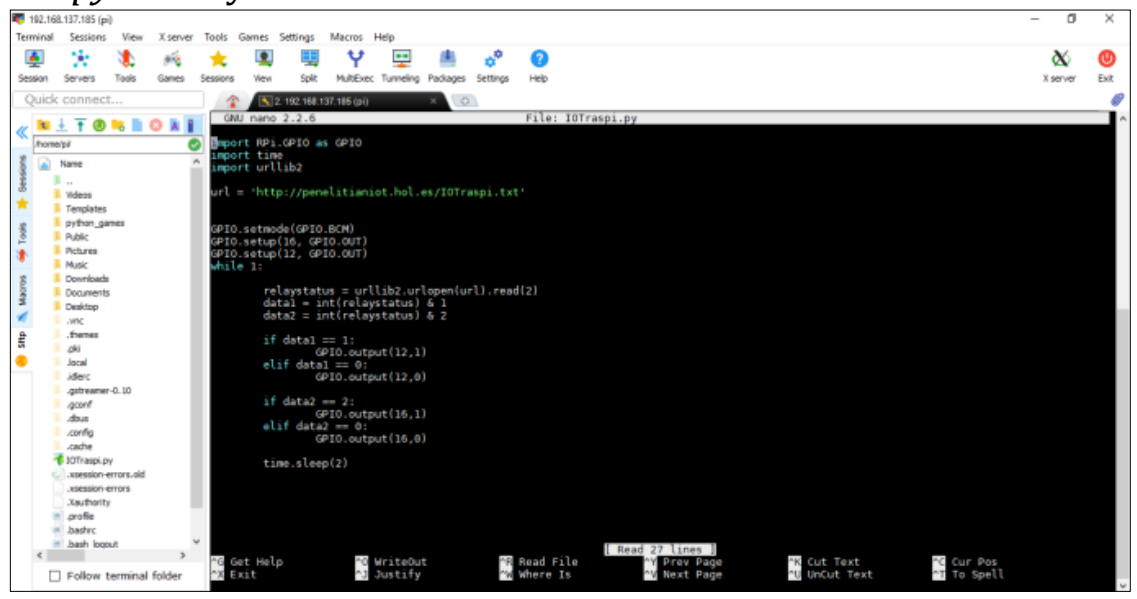

Gambar 7. Script Python

Pada aplikasi ini dapat menampilkan infromasi pengedalian lampu yang nantinya akan dilihat dan dicek langsung oleh petugas menggunakan aplikasi mobile. Berikut ini tampilan aplikasi pengendalian lampu berbasis Mobile:

1. Tampilan mobile posisi lampu mati semua

2. Tampilan mobile posisi 1 bola lampu menyala

3. Tampilan mobile posisi bola lampu ke 2 menyala

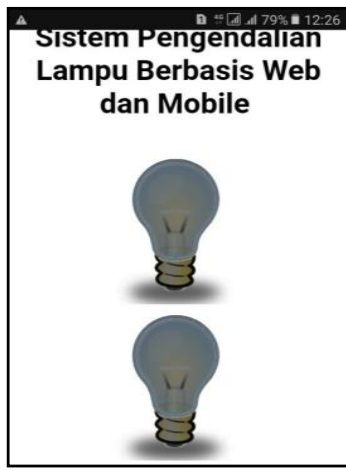

Gambar 10. Tampilan mobile posisi lampu mati semua

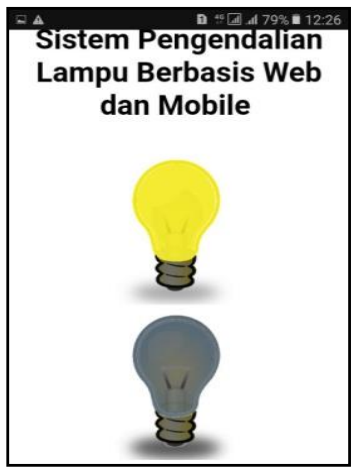

Gambar 11. Tampilan mobile posisi 1 bola lampu menyala

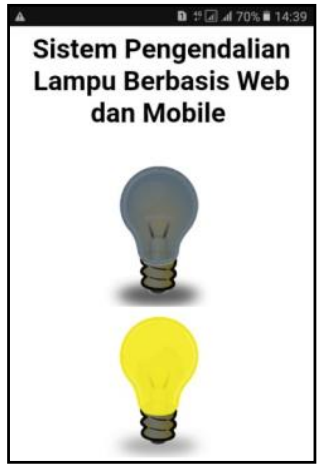

Gambar 12. Tampilan mobile posisi bola lampu ke 2 menyala 


\section{SIMPULAN}

Berdasarkan uraian analisa dan pembahasan, maka disimpulkan dengan memanfaatkan jaringan internet berbasis Internet of things (IoT) sistem ini berhasil mengontrol perangkat lampu melalui koneksi jaringan internet. Internet of things (IoT) dari rancang bangun kendali lampu ini telah berhasil dilakukan dengan dua kondisi kendali tombol satu digunakan untuk menghidupkan satu lampu dan tombol dua digunakan untuk menghidupkan lampu secara bersamaan.

\section{DAFTAR PUSTAKA}

[1] W. A. Muzawi, Rometdo, Yoyon Efendi, "SATIN - Sains dan Teknologi Informasi Sistem Pengendalian Lampu Berbasis Web dan Mobile," SATIN - Sains dan Teknol. Inf., vol. 4, no. 1, 2018.

[2] Kurniawan, "Purwarupa IoT (Internet of things) Kendali Lampu Gedung (Studi Kasus Pada Gedung Perpustakaan Universitas Lampung)," vol. 57, 2016.

[3] R. Muzawi and A. Fauzan, "Prototype Pengontrolan Titik Fokus Panel Surya Terhadap Energi Matahari Secara Otomatis," 2018.

[4] M. K. Arafat, "SISTEM PENGAMANAN PINTU RUMAH BERBASIS Internet of things ( IoT ) Dengan ESP8266," J. Ilm. Fak. Tek. "Technologia," vol. 7, no. 4, pp. 262-268, 2016.

[5] E. D. Meutia, "Internet of things - Keamanan dan Privasi," Semin. Nas. dan Expo Tek. Elektro 2015, pp. 85-89, 2015.

[6] M. A. I. Hakim and Y. H. Putra, "Pemanfaatan Mini Pc Raspberry Pi Sebagai Pengontrol Jarak Jauh Berbasis Web Pada Rumah. Unikom,” pp. 1-6, 2013. 